\title{
Systemic Lidocaine Decreased the Perioperative Opioid Analgesic Requirements but Failed to Reduce Discharge Time After Ambulatory Surgery
}

\author{
Allannah McKay, MD* \\ Antje Gottschalk, MD*+ \\ Annette Ploppa, $\mathrm{MD}^{*} \ddagger$
}

Marcel E. Durieux, MD, PhD*

Danja S. Groves, MD, PhD*
BACKGROUND: In this randomized, blinded, placebo-controlled trial, we evaluated whether systemic lidocaine would reduce pain and time to discharge in ambulatory surgery patients.

METHODS: Sixty-seven patients were enrolled to receive lidocaine or saline infusion perioperatively.

RESULTS: Length of postanesthesia care unit (PACU) stay did not differ between groups. Intraoperative opioid use was significantly less in the lidocaine group, both in the PACU and during the total study period but not after discharge. In the PACU, patients in the lidocaine group reported less pain (visual analog scale score $3.1 \pm 2.04$ vs $4.5 \pm 2.9 ; P=0.043)$. There were no differences in postoperative nausea and vomiting.

CONCLUSION: Perioperative systemic lidocaine significantly reduces opioid requirements in the ambulatory setting without affecting time to discharge.

(Anesth Analg 2009;109:1805-8) ostoperative pain is the most common reason for delay in discharge and unplanned hospital admission after ambulatory surgery. ${ }^{1-3}$

Because postoperative pain is to a large extent an inflammatory phenomenon, administration of systemic local anesthetics, which have inflammatory modulatory properties, ${ }^{4}$ could significantly reduce pain and therefore allow more rapid discharge. ${ }^{5}$ Lidocaine has an excellent safety record when administered by low-dose infusion. ${ }^{5-7}$ However, whereas decreased hospital stay after inpatient surgery has been demonstrated, the effect of intraoperative and early postoperative lidocaine infusion on duration of

From the *Department of Anesthesia, University of Virginia Charlottesville, Virginia; +Department of Anesthesiology and Intensive Care Medicine, University of Muenster, Muenster; and $t D e-$ partment of Anesthesiology and Intensive Care Medicine, Eberhard-Karls University, Tuebingen, Germany.

Accepted for publication August 16, 2009.

Supported by departmental funding.

Marcel E. Durieux is the Section Editor of Anesthetic Pre-Clinical Pharmacology for the Journal. This manuscript was handled by Peter S.A. Glass, Section Editor of Ambulatory Anesthesiology, and Dr. Durieux was not involved in any way with the editorial process or decision.

Reprints will not be available from the author.

Address correspondence to Danja S. Groves, MD, PhD, Department of Anesthesia, University of Virginia, PO Box 800710, Charlottesville, VA 22908-0710. Address e-mail to dgroves@virginia.edu.

Copyright (C) 2009 International Anesthesia Research Society DOI: 10.1213/ANE.0b013e3181be371b stay after ambulatory surgery is not known. Although it seems logical that decreased pain would allow earlier discharge, it is conceivable that, e.g., mild sedating effects of lidocaine could prolong postanesthesia care unit (PACU) admission and interfere with discharge.

We hypothesized that lidocaine, when administered systemically during the operative and early postoperative period, would decrease length of PACU stay (primary outcome measure). Secondary outcome measures were postoperative pain, opioid requirements, and postoperative nausea and vomiting.

\section{METHODS}

After IRB approval, informed consent was obtained from patients 18-75 yr of age (ASA physical status I-III) presenting for outpatient surgery under general anesthesia between August 2004 and August 2006.

Participants were assigned in a double-blind 1:1 ratio using a computer-generated randomization list to receive either a lidocaine or saline placebo infusion. At induction, all patients received $1.5 \mathrm{mg} / \mathrm{kg}$ of lidocaine by slow IV push. The lidocaine infusion (2 $\mathrm{mg} \cdot \mathrm{kg}^{-1} \cdot \mathrm{h}^{-1}$ or equivalent volume of saline as placebo) was started immediately after induction of anesthesia and continued until $1 \mathrm{~h}$ after arrival in the PACU. Anesthetic management during surgery was standardized for opioid use (fentanyl as required and morphine up to $0.15 \mathrm{mg} / \mathrm{kg}$ ), ketorolac (up to $30 \mathrm{mg}$ 
Table 1. Opioid Equivalent Doses

\begin{tabular}{lc}
\hline Morphine & $10 \mathrm{mg} \mathrm{IV}$ \\
Morphine & $30 \mathrm{mg}$ PO \\
Fentanyl & $100 \mu \mathrm{g} \mathrm{IV}$ \\
Meperidine & $75 \mathrm{mg} \mathrm{IV}$ \\
Oxycodone & $20 \mathrm{mg} \mathrm{PO}$ \\
Percocet 5/325 & $6 \mathrm{tabs}$ \\
Hydrocodone & $30 \mathrm{mg}$ PO \\
Vicodin 5/500 & $6 \mathrm{tabs}$ \\
Vicodin $7.5 / 500$ & $4 \mathrm{tabs}$ \\
Tramadol & $150 \mathrm{mg}$ PO \\
\hline
\end{tabular}

IV after hemostasis was obtained if not contraindicated), and prophylaxis for postoperative nausea and/or vomiting (dexamethasone up to $0.1 \mathrm{mg} / \mathrm{kg}$ ). In the PACU, pain was assessed at rest by a visual analog scale every $15 \mathrm{~min}$ and treated with either fentanyl $(0.5-1 \quad \mu \mathrm{g} / \mathrm{kg})$ or morphine (0.01-0.02 $\mathrm{mg} / \mathrm{kg}$ ) when pain was more than 3 on a visual analog scale of $0-10(0=$ no pain, $10=$ more pain imaginable). Nausea was assessed at 15-min intervals and treated with ondansetron or if persistent with promethazine or diphenhydramine. Discharge readiness was assessed by the PACU nurse using the modified Aldrete score every 15 min. ${ }^{8}$ Patients were given a journal to record their analgesic use and level of pain and nausea the first $24 \mathrm{~h}$ after discharge. These data were obtained by a follow-up telephone call.

Twenty-five patients per group were needed to show a $30 \%$ reduction in our primary end point, time to the PACU discharge readiness (based on standard deviation of $50 \mathrm{~min}$ [estimated by chart audit]; $1-\beta=$ $0.8, \alpha=0.05)$. This would translate to a reduction in discharge readiness from $120 \mathrm{~min}$ to $84 \mathrm{~min}$, i.e., somewhat more than half an hour. Based on an expected withdrawal rate of $20 \%$, 67 patients were enrolled in the trial. The primary end point was obtained by subtracting the time of arrival in the PACU from the time that patient discharge readiness was attained using the modified Aldrete score. PACU stay durations follow a 2-parameter lognormal distribution $(P>0.7) .{ }^{9}$ We compared the groups by lognormal transformation followed by calculation of the $95 \%$ confidence interval using the referenced generalized pivotal approach. ${ }^{10}$ Postoperative opioid requirements were calculated for each patient by converting opioids to morphine (mg) IV equivalents (Table 1), and the sample means from treatment and control groups were compared using a 2-tailed $t$-test for independent samples. The presence of nausea and vomiting in each group was analyzed using $\chi^{2}$ test or Fisher's exact test. Data are presented as mean \pm SD, unless stated otherwise.

\section{RESULTS}

Baseline demographic data as well as type and duration of surgical procedures were comparable between the 2 groups (Table 2). Patients in the lidocaine group received $517 \pm 203 \mathrm{mg}$ lidocaine during the infusion.

There was no difference in the primary outcome measure, length of PACU stay, between the groups (133 $\pm 58 \mathrm{~min}$ vs $135 \pm 55 \mathrm{~min} ; P=0.89$ ). The $95 \%$ confidence interval after lognormal transformation was -31 to $39 \mathrm{~min}$.

Intraoperative opioid use (in morphine IV equivalent doses [MEQ]) was reduced by approximately 30\% in the lidocaine group ( $20.52 \pm 10.55$ vs $30.15 \pm 16.59$; $P=0.017$ ), approximately $50 \%$ in the PACU (MEQ: $8.72 \pm 9.54$ vs $15.93 \pm 10.95 ; P=0.015)$, and by approximately $40 \%$ during the total study period (operating room, PACU, and up to $24 \mathrm{~h}$ after discharge) (MEQ: $36.08 \pm 17.13$ vs $59.53 \pm 18.59 ; P=$ 0.002). However, the use of analgesics during the first $24 \mathrm{~h}$ after hospital discharge was not significantly different between the groups (MEQ: $9.17 \pm 9.14$ vs $10.19 \pm 10.45 ; P=0.76$ ) (Fig. 1). In the PACU, patients in the lidocaine group reported less pain at rest (VAS: $3.1 \pm 2.04$ vs $4.5 \pm 2.9 ; P=0.043$ ) (Fig. 2 ). Twenty-four

Table 2. Patient Data

\begin{tabular}{|c|c|c|c|}
\hline & Lidocaine $(n=29)$ & Saline $(n=27)$ & $P$ \\
\hline Sex, male versus female & 24 vs 5 & 21 vs 6 & $0.9\left(\chi^{2}\right.$ test $)$ \\
\hline Age $(y r)$ & $43 \pm 15$ & $46 \pm 15$ & 0.45 (t-test) \\
\hline Weight $(\mathrm{kg})$ & $81 \pm 20$ & $81 \pm 21$ & $0.99(t$-test $)$ \\
\hline $\begin{array}{l}\text { Endotracheal intubation versus } \\
\text { laryngeal mask }(n)\end{array}$ & 23 vs 6 & 24 vs 3 & 0.472 (Fisher's exact test) \\
\hline $\begin{array}{l}\text { Anesthetic agent }(n) \text { (sevoflurane/ } \\
\text { desflurane/isoflurane) }\end{array}$ & 20 vs 9 vs 0 & 18 vs 8 vs 1 & $0.579\left(\chi^{2}\right.$ test $)$ \\
\hline Anesthesia with versus without $\mathrm{N}_{2} \mathrm{O}(n)$ & 10 vs 19 & 4 vs 23 & $0.126\left(\chi^{2}\right.$ test $)$ \\
\hline \multicolumn{4}{|l|}{ Type of surgery } \\
\hline Laparoscopic general $(n)$ & 11 & 13 & \\
\hline Open general $(n)$ & 3 & 3 & \\
\hline Endocrine and breast $(n)$ & 7 & 5 & \\
\hline Laparoscopic gynecology $(n)$ & 4 & 2 & \\
\hline Minor gynecology $(n)$ & 2 & 0 & \\
\hline Urology $(n)$ & 0 & 1 & \\
\hline Plastics $(n)$ & 2 & 1 & \\
\hline Minor ortho $(n)$ & 0 & 1 & \\
\hline Minor ear, nose, throat $(n)$ & 0 & 1 & \\
\hline
\end{tabular}




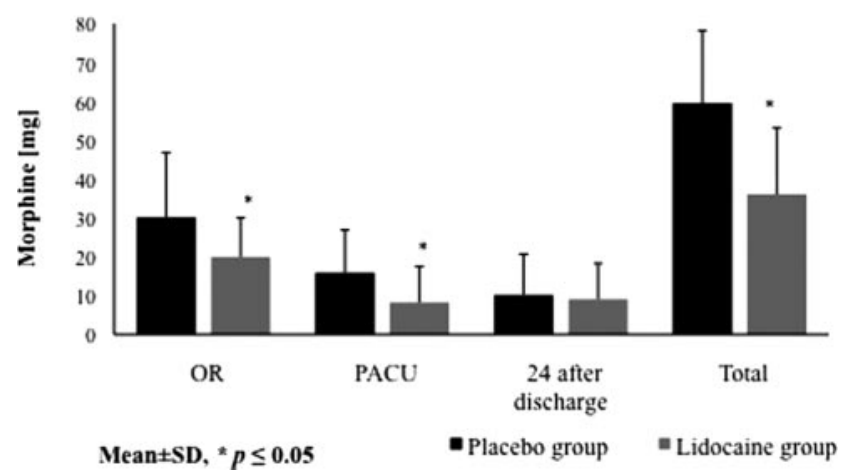

Figure 1. Opioid requirements in the lidocaine group versus the placebo group intraoperatively, in the postanesthesia care unit, for $24 \mathrm{~h}$ after discharge, and total opioid consumption. Results are presented as mean $\pm \mathrm{SD}\left({ }^{*} P \leq 0.05\right)$.

hours later, there were no differences in average pain scores (rest and activity) (VAS: $4.1 \pm 1.8$ vs $4.0 \pm 2.4$; $P=0.97)$.

No statistical differences were found for nausea (10 vs $13 ; P=0.825$ ) and vomiting ( 4 vs $5 ; P=0.733$ ).

There were no serious adverse events recorded. One patient reported dizziness and visual disturbance at the end of the infusion (lidocaine plasma level $2.4 \mu \mathrm{g} / \mathrm{mL}$ ).

\section{DISCUSSION}

Several previous studies have examined the effect of IV lidocaine on recovery after surgery. Martin et al. ${ }^{11}$ reported that a low-dose perioperative IV lidocaine after total hip surgery offers no beneficial effect on postoperative analgesia and does not modify pressure and tactile pain thresholds. In contrast, a metaanalysis of 8 randomized, controlled, clinical trials in patients undergoing abdominal surgery showed that continuous perioperative IV lidocaine administration reduces the duration of postoperative ileus, pain, nausea, and vomiting and shortens hospital stay. ${ }^{12}$ However, none of these studies focused on surgery in the ambulatory setting.

To make the study clinically relevant, we accepted a relatively inhomogeneous study population, reduced standardization of anesthetic (without measurement of minimum alveolar concentration hours) and analgesic regimen, and lack of certain outcome data (recovery of gastrointestinal function and resumption of normal activities of daily living). Still, we found an opioid-sparing effect in the perioperative and early postoperative period. These effects did not affect recovery time by more than half an hour. The opioid-sparing effect of IV lidocaine did not affect the

\section{VAS scores in PACU}

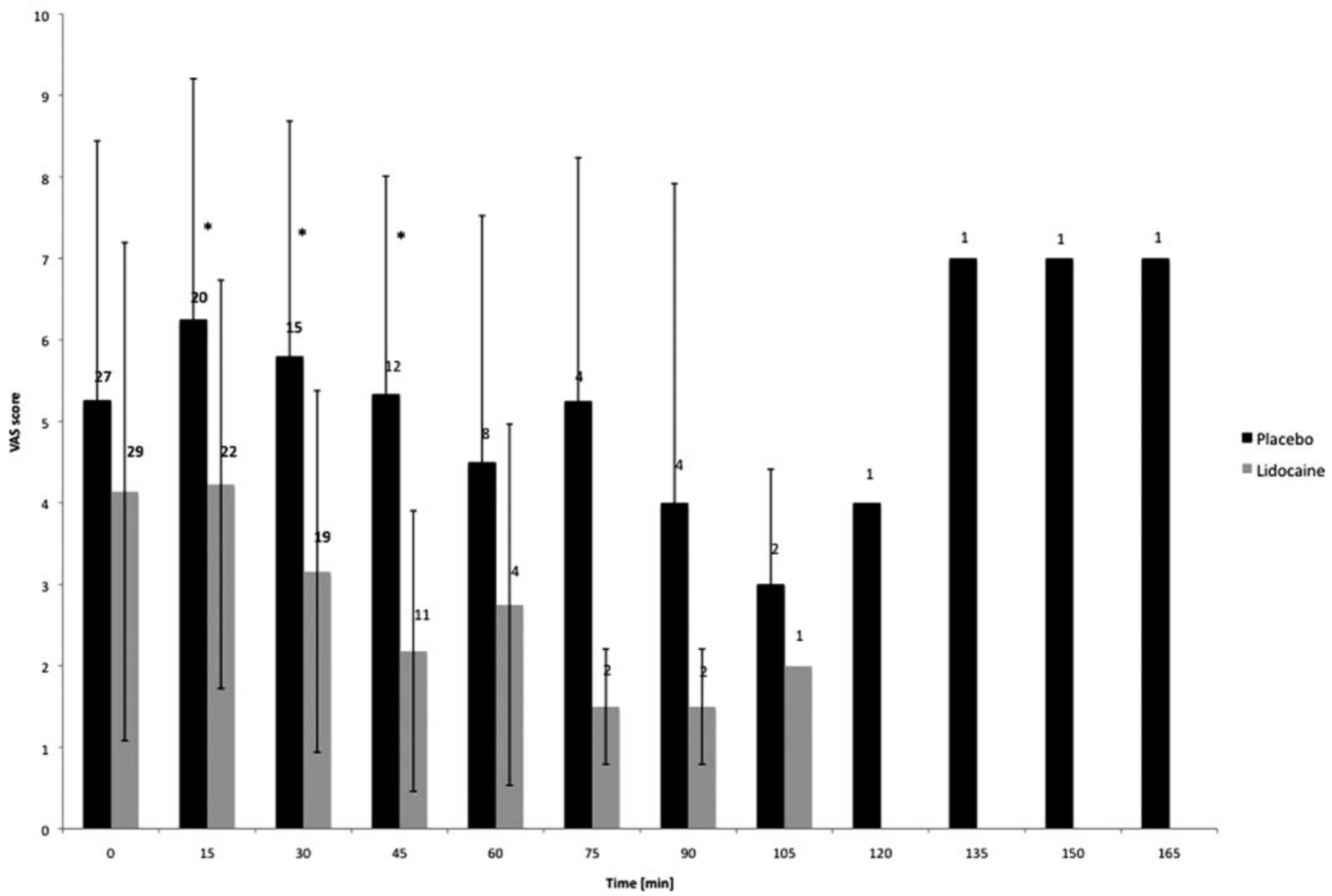

Figure 2. Visual analog scale scores in the postanesthesia care unit over time. Results are presented as mean \pm SD $\left({ }^{*} P \leq 0.05\right.$ between the groups). Numbers above columns indicate group size. 
incidence of nausea and vomiting in our study population. The nonhomogeneous study population and the administration of a lidocaine bolus before the administration of the study medication in both groups may have minimized possible differences between the 2 study groups. However, because it is safe, inexpensive, and does not require additional monitoring to that routinely provided in the PACU setting, lidocaine offers a potential therapeutic approach for perioperative analgesia in the outpatient setting.

\section{ACKNOWLEDGMENTS}

The authors thank Dr. Franklin Dexter for assistance in the statistical analysis of the data.

\section{REFERENCES}

1. Shaikh S, Chung F, Imarengiaye C, Yung D, Bernstein M. Pain, nausea, vomiting and ocular complications delay discharge following ambulatory microdiscectomy. Can J Anaesth 2003;50: $514-8$

2. Shirakami G, Teratani Y, Namba T, Hirakata H, TazukeNishimura M, Fukuda K. Delayed discharge and acceptability of ambulatory surgery in adult outpatients receiving general anesthesia. J Anesth 2005;19:93-101

3. Chung F, Mezei G. Factors contributing to a prolonged stay after ambulatory surgery. Anesth Analg 1999;89:1352-9
4. Hollmann MW, Durieux ME. Local anesthetics and the inflammatory response: a new therapeutic indication? Anesthesiology 2000;93:858-75

5. Kaba A, Laurent SR, Detroz BJ, Sessler DI, Durieux ME, Lamy $\mathrm{ML}$, Joris JL. Intravenous lidocaine infusion facilitates acute rehabilitation after laparoscopic colectomy. Anesthesiology 2007;106:11-8

6. Herroeder S, Pecher S, Schonherr ME, Kaulitz G, Hahnenkamp K, Friess H, Bottiger BW, Bauer H, Dijkgraaf OG, Durieux ME, Hollmann MW. Systemic lidocaine shortens length of hospital stay after colorectal surgery: a double-blinded, randomized, placebo-controlled trial. Ann Surg 2007;246:192-200

7. Koppert W, Weigand M, Neumann F, Sittl R, Schuettler J, Schmelz M, Hering W. Perioperative intravenous lidocaine has preventive effects on postoperative pain and morphine consumption after major abdominal surgery. Anesth Analg 2004;98: 1050-5

8. Aldrete JA, Kroulik D. A postanesthetic recovery score. Anesth Analg 1970;49:924-34

9. Dexter F, Penning DH, Traub RD. Statistical analysis by MonteCarlo simulation of the impact of administrative and medical delays in discharge from the postanesthesia care unit on total patient care hours. Anesth Analg 2001;92:1222-5

10. Chen $\mathrm{YH}$, Zhou $\mathrm{XH}$. Interval estimates for the ratio and difference of two lognormal means. Stat Med 2006;25:4099-113

11. Martin F, Cherif K, Gentili ME, Enel D, Abe E, Alvarez JC, Mazoit JX, Chauvin M, Bouhassira D, Fletcher D. Lack of impact of intravenous lidocaine on analgesia, functional recovery, and nociceptive pain threshold after total hip arthroplasty. Anesthesiology 2008;109:118-23

12. Marret E, Rolin M, Beaussier M, Bonnet F. Meta-analysis of intravenous lidocaine and postoperative recovery after abdominal surgery. Br J Surg 2008;95:1331-8 